\title{
Perinatal Dissociation and Post-traumatic Stress Disorder among Mothers of Preterm Infants: A Comparative Study
}

\author{
Sahar Ellouze ${ }^{1, *}$, Jihène Aloulou ${ }^{1}$, Najla Halouani ${ }^{1}$, Afef Ben Thabet ${ }^{2}$, Amira Bouraoui ${ }^{2}$, \\ Abdellatif Gargouri ${ }^{2}$, Othmen Amami ${ }^{1}$ \\ ${ }^{1}$ Psychiatry "B" Department, Hedi Chaker University Hospital, Tunisia \\ ${ }^{2}$ Neonatology Department, Hedi Chaker University Hospital, Tunisia
}

Copyright $(2017$ by authors, all rights reserved. Authors agree that this article remains permanently open access under the terms of the Creative Commons Attribution License 4.0 International License

\begin{abstract}
Preterm delivery is a particularly challenging experience that can be experienced by mothers as a traumatic event, causing dissociative reactions and authentic post-traumatic stress disorder (PTSD). In this work, we proposed to study the prevalence of perinatal dissociation and PTSD in mothers of preterm babies compared to a control group of mothers of term babies and to identify factors that may contribute to the occurrence of perinatal dissociation and PTSD following premature childbirth. We conducted a cross-sectional and comparative study, including 97 mothers of premature babies and 80 controls. We used the Perinatal Posttraumatic Stress Disorder Questionnaire to screen for PTSD, the peri-traumatic dissociation questionnaire to measure the level of perinatal dissociation, and the Perinatal Risk Inventory to assess perinatal risk. Compared to mothers of term infants, mothers of preterm infants had significantly higher rates of peri-traumatic dissociation and PTSD. Our results are consistent with previous studies, and add additional credit to the traumatic nature of preterm delivery. Setting up specific support modalities seems essential in the case of premature births in order to ensure a better quality of mother-child interactions and optimal development of the child.
\end{abstract}

Keywords Post-traumatic Stress Disorders, Peritraumatic Dissociation, Premature, Child-birth

\section{Introduction}

The advance in perinatal and neonatal care has considerably increased the survival rates of preterm infants. However, preterm birth is still the leading cause of infant mortality, pediatric morbidity, and long-term disability [1].

Preterm birth is also considered as a stressful and emotionally demanding experience that has short and long term impact on family, especially on mothers.

Several studies have explored maternal experiences, precisely as depression or persistent anxiety [2, 3]. It was only recently that the experience of having a premature child was explored as a traumatic experience. Thus, several authors have highlighted the traumatic nature of having a preterm born child, which can potentially lead to postpartum posttraumatic stress disorder (PTSD) [4, 5].

Many factors have been identified as stressful for mothers undergoing a preterm delivery; among them is the infant's immaturity [6], the medical condition of the premature newborn child $[7,8]$, the fear for one's or for the child's life [9], and the long, hard and painful labor [10].

In recent years, particular attention has been paid to the predictive role of psychological phenomena occurring during or directly after various traumatic incidents. Dissociation, experienced at the time of traumatic birth, appears to be one of the most important predictors of subsequent PTSD symptoms among mothers [10-12].

To our knowledge, few studies have examined PTSD symptoms following preterm childbirth. None of these studies address peritraumatic dissociation in this particular case of premature delivery.

The first proposal in this study was to determine the frequency of significant dissociative experience during preterm delivery compared with full-term delivery in Tunisian women, to identify factors that may contribute to the occurrence of perinatal dissociation and to investigate its contributive role to the development of PTSD symptoms following premature childbirth. The second proposal was to measure the prevalence of PTSD among mothers of preterm infants in comparison with a control group and to identify predictors of clinically relevant PTSD symptomatology following premature childbirth.

\section{Materials and Methods}

\subsection{Participants}

The study was performed at the outpatient unit of 
neonatology at the University Hospital Hedi Chaker of Sfax in Tunisia. It was designed as a cross sectional, descriptive and analytical study conducted during a 3 year-period between July 2012 and June 2015.

The study group consisted of 97 mothers who had delivered a preterm infant born prior to 37 weeks gestation, during the last 1 to 7 months. Mothers who consented to the study and to the use of their data for research purposes have been considered for inclusion in the study. Exclusion criteria were mothers who delivered by caesarean section under general anesthesia, those with severe organic disease or decompensated psychiatric history and infant malformation, chromosomic abnormality and foetopathy.

Eighty mothers of full-term infants ( $\geqslant 37$ weeks gestation) were enrolled as controls. Exclusion criteria were severe organic disease or psychiatric disorder in mothers.

Infants were case matched for age. Mothers were case matched for age, marital status and socioeconomic level.

\subsection{Instruments}

The survey questionnaire booklet contained a number of previously validated research instruments.

\subsubsection{The Perinatal Posttraumatic Stress Disorder (PTSD) Questionnaire (PPQ) [12, 13]}

The PPQ is a 14-item self-rating questionnaire designed for parents of high-risk infants, to assess the presence of traumatic memories about birth. Items are based on the DSM-IV diagnostic criteria for PTSD [14] and relate to intrusive memories, avoidance and arousal symptoms. Questions are retrospective. All items are ranked from 0 (not at all) to 4 (more than one month), to yield a total score between 0 and 56. A threshold score of 19, beyond which mothers are identified as requiring therapeutic management was used as an indicator of PTSD.

\subsubsection{Peritraumatic Dissociative Experiences Questionnaire (PDEQ) [15]}

The PDEQ consists of 10 items self-report inventory used to assess dissociation that occurred at the time of a trauma. In the current study, the delivery was set as the critical event. Women were asked, retrospectively, about the occurrence of events during labor, during birth or immediately after the birth. Phenomena assumed to be dissociative are related to constructs of depersonalization, derealization, altered sense of time, and altered sense of body image. Mothers were requested to fill in a 5-point Likert response scale, from (not at all true) to 5 (extremely true), resulting in a score range from 10 to 50. A score above 24 is indicative of a significant dissociation.

\subsubsection{The Perinatal Risk Inventory (PERI) [16]}

The perinatal risk inventory is an inventory of 18 items used to describe the gravity of perinatal problems and the magnitude of survival risks, on the basis of several perinatal factors such as the Apgar index, gestational age, weight, head growth, electroencephalogram, ultra-sonogram, and ventilation. Since this index is strongly correlated with length of hospital stay and intensive care procedures, it provides a rough indication of the stress experienced by the premature infant. We used a clinical cut off point (4 or more points), thereby separating low-risk and high-risk newborn infants.

\subsection{Procedure}

Mothers who are eligible for the study were asked to reply to a socio-demographic and obstetrical characteristics questionnaire. The questionnaire was subdivided into four sections regarding epidemiologic data, course of pregnancy, circumstances of the delivery, as well as the post discharge period.

Infant birth history, time of gestation at delivery, obstetrical complications and complications with the baby were collected from hospital records. The completion of the questionnaire took approximately 20 minutes.

\subsection{Statistical Analysis}

Statistical analysis was performed using IBM SPSS Statistics for Windows, Version 21.0. Descriptive characteristics are presented, with categorical data as number and percentage and continuous data as mean and standard deviation (SD). To compare frequencies and evaluate correlations, Fisher exact test and chi-square tests were performed. Bivariate analysis was undertaken to compare the two groups of preterm and full-term mothers. A p value $<0.05$ was considered statistically significant.

\section{Results}

\subsection{Sample Characteristics}

Mean maternal age at delivery was 30.2 years (SD 5.8 years) and average gestational age was 32.82 weeks (SD 4.9 weeks). Maternal and child characteristics are shown in Table 1. 
Table 1. Sample characteristics

\begin{tabular}{|c|c|c|c|c|c|c|}
\hline & \multicolumn{2}{|c|}{ Premature cohort $(\mathrm{n}=97)$} & \multicolumn{2}{|c|}{ Term control cohort $(\mathrm{n}=80)$} & \multicolumn{2}{|c|}{ Total sample $(\mathrm{n}=177)$} \\
\hline & Mean (SD) & $\%$ & Mean (SD) & $\%$ & Mean (SD) & $\%$ \\
\hline \multicolumn{7}{|c|}{ Mothers characteristics } \\
\hline Married & & 99 & & 100 & & 99.4 \\
\hline Educational level $\leq$ secondary & & 81.4 & & 35 & & 60.5 \\
\hline Unemployed outside the home & & 76.3 & & 71.3 & & 74 \\
\hline Immigrant mothers & & 20.6 & & 11.3 & & 16.4 \\
\hline Primiparous & & 35.1 & & 47.5 & & 40.7 \\
\hline History of perinatal death & & 8.2 & & 3.8 & & 6.2 \\
\hline Unexpected prematurity & & 56.7 & & & & \\
\hline Caesarean section & & 77.3 & & 52.5 & & 66.1 \\
\hline $\begin{array}{l}\text { Avoidance of sexual intercourse } \\
\text { postpartum }\end{array}$ & & 42.3 & & 16.3 & & 30.5 \\
\hline \multicolumn{7}{|c|}{ Child characteristics } \\
\hline Age & $3 \pm 1.74$ & & $3.5 \pm 1.8$ & & $3.2 \pm 1.8$ & \\
\hline Length of hospital stay in days & $19.1 \pm 18.2$ & & $2.2 \pm 3.8$ & & $11.7 \pm 16.2$ & \\
\hline Second hospitalization & & 18.5 & & 3.8 & & 11.9 \\
\hline PERI score & $3.9 \pm 2.6$ & & & & & \\
\hline high-risk newborn infants & & 47.4 & & & & \\
\hline
\end{tabular}

Table 2. Perinatal dissociation among preterm and full term infant's mothers

\begin{tabular}{|c|c|c|c|c|c|}
\hline & \multicolumn{2}{|c|}{ Mothers of preterm infants } & \multicolumn{2}{|c|}{ Mothers of full-term infants } & \multirow{2}{*}{ p value } \\
\cline { 2 - 5 } & $\mathrm{N}$ & $\%$ & $\mathrm{~N}$ & $\%$ & \multirow{2}{*}{0.014} \\
\hline QEDP score $<24$ & 77 & 79.4 & 74 & 7.5 & \\
\hline QEDP score $\geq 24$ & 20 & 20.6 & 6 & \multicolumn{2}{|c|}{0.001} \\
\hline QEDP mean score & \multicolumn{2}{|c|}{$16.36 \pm 7.05$} & \multicolumn{2}{|c|}{$13.29 \pm 5.13$} & \\
\hline
\end{tabular}

Table 3. PTSD among mothers of premature and full term infants

\begin{tabular}{|c|c|c|c|c|c|}
\hline & \multicolumn{2}{|c|}{ Mothers of preterm infants } & \multicolumn{2}{|c|}{ Mothers of full-term infants } & \multirow{2}{*}{$\mathrm{p}$ value } \\
\hline & $\mathrm{N}$ & $\%$ & $\mathrm{~N}$ & $\%$ & \\
\hline PPQ score $<19$ & 54 & 55.7 & 66 & 82.5 & \multirow{2}{*}{$<0.001$} \\
\hline PPQ score $\geq 19$ & 43 & 44.3 & 14 & 17.5 & \\
\hline PPQ mean score & \multicolumn{2}{|c|}{$19.39 \pm 13.59$} & \multicolumn{2}{|c|}{$11.22 \pm 9.48$} & $<0.001$ \\
\hline
\end{tabular}

\subsection{Dissociative Experience during Premature Childbirth}

The average score of PDEQ was 16.36 (SD = 7.05). A total of $20.6 \%$ of mothers of preterm infants experienced significant dissociation (PDEQ $\geqslant 24$ ), during or shortly after delivery. Dissociative experience occurrence was significantly more common in women that did not expect to give birth prematurely ( $\mathrm{p}=<0.001$ ) and those with high perinatal risk infant $(p=0.023)$. Perinatal dissociation was also significantly correlated to PTSD in categorical ( $<<$ $0.001)$ and dimensional analysis ( $\left.\mathrm{p}<0.001 ; \mathrm{r}=0.784^{* *}\right)$.

Prevalence of perinatal dissociation and scores of PDEQ were significantly greater for the preterm group (table 2).

\subsection{PTSD}

The prevalence of PTSD was $44.3 \%$ in our sample. The occurrence of PTSD following premature childbirth was significantly correlated with immigration ( $p<0.001)$, a previous history of perinatal death $(\mathrm{p}=0.001)$, unexpected prematurity ( $p<0.001)$, length of hospital stay ( $p=0.019$ ), second hospitalization $(p=0.035)$ and avoidance of sexual intercourse postpartum ( $p=0.002)$. The PPQ score differed significantly between high and low risk premature infants ( $\mathrm{p}$ $=0.001$ ). The average PPQ score was significantly higher in mothers of preterm infants compared with control group (table 3). 


\section{Discussion}

The present findings indicate higher prevalence of dissociation among mothers of preterm infants in comparison with the control group. This result corroborate the literature. Indeed, although the assessment of perinatal dissociation during premature childbirth is a rarity in the literature, prematurity has emerged as a significant predictive factor of perinatal dissociation in studies of heterogeneous populations of parturient women [17]. In fact, during a premature birth, cognitive appraisal of preterm labor as unmanageable, negative emotions, feelings of helplessness, fear of death or loss of control and fear of receiving bad news can lead to significant emotional distress, which parturient women attempt to escape by dissociative symptoms $[17,18]$.

In our study, the prevalence of PTSD in mothers after premature delivery was $44.3 \%$. This figure falls within the prevalence range found in the literature $[4,5,19,20]$ for PTSD in mothers of preterm infants ranging from 30 to $53 \%$ of the population concerned. Pierrehumbert et al. [19], in a comparative study of 50 families of preterm infants and 25 control families of term infants, reported significantly higher PPQ scores in mothers of preterm infants, compared to controls. Premature birth is currently recognized as one of the risk factors for post-traumatic post-partum stress symptoms [21, 22].

Peri-traumatic dissociation is considered as one of the most reliable predictors of PTSD, regardless of the nature of the traumatic event [23, 24]. For Duijsens et al. [25], this phenomenon results from a failure of integration, which paves the way for the perpetuation of the traumatic experience in the long term and therefore promotes the development of PTSD. In the field of obstetrics, many studies have highlighted the involvement of dissociative experiences at the time of delivery in the subsequent development of PTSD [10, 11, 25]. Moreover, this association was significant in our study in categorial and dimensional analysis ( $p<0.001$ ). In order to explain this association between perinatal dissociation and subsequent development of PTSD, Gershuny et al. [26] suggested that this causal relationship would be mediated primarily by fear of death and fear of losing control, reflecting the importance of the subjective distress felt by the mother at the time of delivery. This subjective experience of childbirth has been widely criticized in the literature, and its indirect role in the development of PTSD via dissociative symptoms is now well documented in a term delivery [27, 28]. This result could be superimposed to the case of premature labor. Neurobiology data could better explain these assumptions [29]. Faced with a birth experienced as traumatic, the parturient undergoes an important secretion of stress hormones. The overflow of adaptation mechanisms would be responsible for a noradrenergic flooding, all the more important as the stress level is high. Two phenomena could then take place. On the one hand, the brain, faced with this neurovegetative storm, will set up neurobiological safeguard mechanisms via a release of endorphins and ketamine-like substances that will lead to disjunction of the emotional circuit and a dissociative state. On the other hand, this hyper adrenergy will promote, in addition to hyper-vigilance syndrome, mechanisms of hyper-encoding and memory consolidation, notably at the amygdala level, responsible for traumatic memory and repetitive syndrome in PTSD.

Moreover, perinatal dissociation, as well as more frequent occurrence of PTSD were significantly associated with a high perinatal risk in the present study. In this regard, Zambaldi et al [17] reported that the occurrence of medical complications for the mother or her child at the time of delivery significantly contributes to the development of perinatal dissociation. The most implicated medical complications in this study were low birth weight, respiratory problems, infections and neonatal jaundice. Regarding the association PTSD following preterm delivery and severity of prematurity, it remain a subject of controversy in the literature with disparate results according to the studies. For Holditch-Davis et al. [2], the degree of severity of preterm birth plays no role in the occurrence of post-traumatic stress symptoms. Other studies [19, 20], however, suggest an association between PTSD and the severity of prematurity, as was the case in our study. This result could be explained by the frequent use, in cases of high perinatal risk, of heavy intensive care with prolonged hospitalization and frequent separation with the newborn. These stress factors can lead to the invasion of mothers by anxieties of death and abandonment, as well as traumatic images, echoing the lack of representations of the still unknown child and could favor the development of PTSD [30]. Gray et al. [31] reported that the stress experienced by mothers of premature babies was significantly correlated with the birth weight at birth, the indication of home oxygen therapy, the possible use of surgical treatment for retinopathy premature bleeding and possible intraventricular hemorrhage. All these variables are actually evaluated by the PERI.

In our series, peri-traumatic dissociation and PTSD were significantly associated with unexpected prematurity (p $<0.001)$. This observation highlights the important impact of the unexpected occurrence of premature labor in the emergence of dissociative reactions and subsequent PTSD. This refers to the definition of trauma, which is characterized by its sudden, violent, brutal, unexpected and unprepared occurrence [32].

The occurrence of PTSD was significantly correlated with a history of perinatal death $(\mathrm{p}=0.001)$. A perinatal death is currently recognized as one of the most traumatic events a mother could experience [33]. This traumatic experience, along with other adverse events with traumatic impact in general, was considered by authors [34, 35] as predictive factors for the development of PTSD following a new traumatic confrontation, namely premature birth in our context, while favoring its subsequent psychic resonance [36]. In a study conducted in 2014 by Goutaudier et al. [4], women who have experienced a traumatic event within 24 
months prior preterm delivery had a mean score at the Impact of Event Scale-Revised (IES-R) significantly higher than those who have not experienced such type of event. This risk is all the more important as the number of traumatic events is high [37]. Moreover, the study by Chang et al. [38] showed that the risk of developing PTSD was significantly higher in mothers of preterm infants with a history of two or more abortions compared to those with a single or no prior abortion.

In our study, the occurrence of PTSD was significantly correlated with the notion of mothers' immigration (p $<0.001$ ). These mothers constitute in the literature [39] a fragile population that is particularly vulnerable to psychiatric disorders in general, and to PTSD in particular. Some authors [40] have emphasized the impact of the maternal grandmother's absence. In many societies, including Tunisian society, grandmother plays a major role in child care during the postnatal period.

Concerning the role of the mode of delivery in the occurrence of PTSD, opinions diverge. For some authors [4, 11, 41], caesarean delivery was considered a predictive factor for PTSD. For others [42-44], caesarean deliveries, whether scheduled or performed in emergency, significantly increased stress scores without favoring PTSD. For other authors [41, 45], the mode of delivery and obstetric procedures were neither associated nor predictive of PTSD following childbirth. However, they became so in certain circumstances, in particular as a function of the subjective experience of childbirth [11]. Our findings corroborate this latter hypothesis since the occurrence of PTSD was not correlated with caesarean delivery.

The duration of hospitalization of premature child in the neonatology department was significantly correlated with the occurrence of PTSD in mothers $(p=0.019)$. This hospitalization of newborns immediately after birth is a difficult and anxiogenic situation for mothers [46, 47]. The length of their stay in a hospital unit, which reflects the seriousness of their state of health, would give rise to periods of doubt as to the evolution of prematurity, disappointment with the announcement of possible complications [48] and difficulty in the development of the first links [49]. These concerns, as well as the tiresome expectation of improvement, would provide psychological upheaval for mothers and could promote the development or maintenance of post-traumatic stress symptoms. The notion of re-hospitalization of children was also significantly associated with the occurrence of PTSD in our study $(\mathrm{p}=0.035)$. This re-hospitalization, witnessing the vulnerability and fragility of the premature child, will re-expose the mother to the circumstances of preterm delivery, and revive in her the anxieties experienced during her child's stay in neonatology. This stress factor, occurring in a field already weakened by the experience of preterm delivery and its consequences, could then promote the development of PTSD [37].

The notion of avoidance of postpartum sex for fear of pregnancy was significantly associated with the occurrence of PTSD ( $p=0.002)$. It is a specific manifestation of the post-obstetric traumatic symptomatology invoked by some authors [50]. This avoidance behavior also represents a symptom referred to as PTSD C2 in DSM 5 [51], the sexual relation being the external recall index, awakening the memories

\section{Conclusions}

Our results are consistent with previous studies, and add additional credit to the traumatic nature of preterm delivery.

This potentially traumatic impact of premature childbearing persists over time and can thus destabilize the mother in her parenting under construction and hinder the quality of the mother-child interactions and consequently the development of the child.

Identifying women at risk, routinely screening for symptoms of post-traumatic stress, educating health professionals about these disorders, and setting up specific support modalities for premature births are essential. These measures will make it possible to ensure a better psychological and emotional availability of mothers, so that secure mother-infant attachment is established harmoniously.

\section{Acknowledgements}

The authors acknowledge all the staff of the outpatient unit of neonatology at the University Hospital Hedi Chaker of Sfax in Tunisia. We also thank all the mothers who kindly agreed to participate in this study.

The authors declare that there is no conflict of interest.

\section{REFERENCES}

[1] McCormick MC, Litt JS, Smith VC, Zupancic JAF (2011). Prematurity: an overview and public health implications. Annu Rev Public Health, 32:367-79.

[2] Holditch-Davis D, Bartlett TR, Blickman AL, Miles MS (2003). Posttraumatic stress symptoms in mothers of premature infants. J Obstet Gynecol Neonatal Nurs, 32(2):161-71.

[3] Singer LT, Salvator A, Guo S, Collin M, Lilien L, Baley J (1999). Maternal psychological distress and parenting stress after the birth of a very low-birth-weight infant. J Am Med Assoc, 28(9):799-805.

[4] Goutaudier N, Séjourné N, Bui E, Cazenave N, Chabrol H (2014). L'accouchement prématuré: une naissance traumatique? Symptômes de stress posttraumatique et variables associées. Gynecol Obstet Fertil, 42:749-54.

[5] Gamba Szijarto S, Forcada Guex M, Borghini A, 
Pierrehumbert B, Ansermet, Müller Nix C (2009). État de stress post-traumatique chez les mères et chez les pères d'enfants prématurés: similitudes et différences. Neuropsychiatrie de l'enfance et de l'adolescence, 57:385-91.

[6] Forcada-Guex M, Borghini A, Pierrehumbert B, Ansermet F, Muller-Nix C (2011). Prematurity, maternal posttraumatic stress and consequences on the mother-infant relationship. Early Human Development, 87:21-6.

[7] Stramrood CA, Wessel I, Doornbos B, Aarnoudse JG, Van den Berg PP, Schultz WC, et al. (2011). Posttraumatic stress disorder following preeclampsia and PPROM: a prospective study with 15 months follow-up. Reprod Sci, 18(7):645-53.

[8] Hudek-Knezevic J, Kardum I (2009). Five-factor personality dimensions and 3 health related personality constructs as predictors of health. Croat Med J, 50(4):394-402.

[9] Imsiragic AS, Begic D, Martic-Biocina S (2009). Acute stress and depression 3 days after vaginal delivery-observational, comparative study. Coll Antropol, 33(2):521-7.

[10] Olde E, Van Der Hart O, Kleber RJ, Van Son M, Wijnen H, Pop V (2005). Peritraumatic Dissociation and Emotions as Predictors of PTSD Symptoms Following Childbirth. Journal of Trauma \& Dissociation, 6(3):125-42.

[11] Van Son M, Verkerk G, Van der Hart O, Komproe I, Pop V (2005). Prenatal depression, mode of delivery and perinatal dissociation as predictors of posttraumatic stress: An empirical study. Clin Psychol Psychotherapy, 12:297-312.

[12] DeMier RL, Hynan MT, Harris HB, Manniello RL (1996). Perinatal stressors as predictors of symptoms of posttraumatic stress in others of infants at high-risk. J Perinatol, 16:276-80.

[13] Quinnell F, Hynan M (1999). Convergent and discriminant validity of the Perinatal PTSD. Questionnaire (PPQ): a preliminary study. J Trauma Stress, 12(1):193-9.

[14] American Psychiatric Association (1994). Diagnostic and statistical manual of mental disorder. IVed: American Psychiatric Association. Washington, DC.

[15] Marmar CR, Weiss DS, Schlenger WE, Fairbank JA, Jordan BK, Kulka RA, et al. (1994). Peritraumatic dissociation and posttraumatic stress in male Vietnam theater veterans. Am J Psychiatry, 151:902-7.

[16] Scheiner AP, Sexton ME (1991). Prediction of developmental outcome using a perinatal risk inventory. Pediatrics, 41(3):209-18.

[17] Zambaldi CF, Cantilino A, Farias JA, Moraes GP, Sougey EB (2011). Dissociative experience during childbirth. Journal of Psychosomatic Obstetrics and Gynecology, 32(4):204-9.

[18] Boudou M, Séjourné N, Chabrol H (2007). Douleur de l'accouchement, dissociation et détresse périnatales comme variables prédictives de symptômes de stress posttraumatique en post-partum. Gynecol Obstet Fertil, 35:1136-42.

[19] Pierrehumbert B, Nicole A, Muller-Nix C, Forcada-Guex M, Ansermet F (2003). Parental post-traumatic reactions after premature birth: implications for sleeping and eating problems in the infant. Arch Dis Child Fetal Neonatal, 88:400-4.

[20] Muller-Nix C, Forcada-Guex M, Pierrehumbert B, Jaunin L, Borghini A, Ansermet F (2004). Prematurity, maternal stress and mother-child interactions. Early Human Development,
9:145-58.

[21] Soderquist J, Wijma B, Wijma K (2006). The longitudinal course of post-traumatic stress after childbirth. J Psychosom Obstet Gynaecol, 27(2):113-19.

[22] Dulguérian MR (2012). Vécu émotionnel des parents d'enfants nés prématurément et aspects psychologiques. EMC pédiatrie, $7(2): 1-6$

[23] Ozer EJ, Best SR, Lipsey TL, Weiss DS (2003). Predictors of posttraumatic stress disorder and symptoms in adults: A meta-analysis. Psychological Bulletin, 129:52-73.

[24] Delahanty DL, Royer DK, Raimonde AJ, Spoonster E (2000). Injury severity, prior trauma history, urinary cortisol levels, and acute PTSD in motor vehicle accident victims. J Anxiety Disord, 17:149-64.

[25] Duijsens IJ, Eurelings-Bontekoe EH, Diekstra RF (1996). The VKP, a self-report instrument for DSM-III-R and ICD-10 personality disorders: construction and psychometric properties. Person Individ Diff, 20:171-82.

[26] Gershuny BS, Cloitre M, Otto MW (2003). Peritraumatic dissociation and PTSD severity: Do event-related fears about death and control mediate their relation? Behaviour Research and Therapy, 41:157-66.

[27] Montmasson H, Bertrand P, Perrotin F, El-Hage W (2012). Facteurs prédictifs de l'état de stress post-traumatique du postpartum chez la primipare. J Gynecol Obstet Biol Reprod, 41:553-60.

[28] Ayers S, Joseph S, McKenzie-McHarg K, Slade P, Wijma K (2008). Posttraumatic stress disorder following childbirth: current issues and recommendations for future research. J Psychosom Obstet Gynecol, 29:240-50.

[29] Ducrocq F, Vaiva G (2005). De la biologie du trauma aux pistes pharmacologiques de prévention secondaire de l'état de stress post-traumatique. L'Encéphale, 31:212-26.

[30] Meyer EC, Garcia Coll CT, Seifer R, Ramos A, Kilis E, Oh W (1995). Psychological distress in mothers of preterm infants. Developmental and Behavioral Pediatrics, 16:12-7.

[31] Gray PH, Edwards DM, O'Callaghan MJ, Cuskelly M (2012). Parenting stress in mothers of preterm infants during early infancy. Early Human Development, 88:45-9.

[32] Maury C, Abbal T, Moro MR (2016). Clinique du psychotraumatisme et erreur de diagnostic en situation transculturelle. Annales Médico-Psychologiques, 174(4):266-73.

[33] Flenady V, Wilson T (2012). Support for mothers, fathers and families after perinatal death. Int J Evid Based Healthc, 10:233-4.

[34] Andersen LB, Melvaer LB, Videbech P, Lamont RF, Joergensen JS (2012). Risk factors for developing post-traumatic stress disorder following childbirth: a systematic review. Nordic Federation of Societies of Obstetrics and Gynecology, 91:1261-72.

[35] Ford E, Ayers S, Bradley R (2010). Exploration of a cognitive model to predict post-traumatic stress symptoms following childbirth. J Anxiety Disord, 24:353-9.

[36] Auxémérya Y (2012). L'état de stress post-traumatique comme 
conséquence de l'interaction entre une susceptibilité génétique individuelle, un évènement traumatogène et un contexte social. L'Encéphale, 38:373-80.

[37] Lebigot F (2009). Le traumatisme psychique. Stress et trauma, 9(4):201-4.

[38] Chang HP, Chen JY, Huang YH, Yeh CJ, Huang JY, Su PH et al. (2016). Factors Associated with Post-Traumatic Symptoms in Mothers of Preterm Infants. Archives of Psychiatric Nursing, 30:96-101.

[39] Perrina AS, Drainb E, Sarotc A, Moro MR (2016). Comment soutenir l'arrivée au monde d'un enfant de mère migrante dans une maternité française: entre urgence somatique et urgence psychiatrique. Neuropsychiatrie de l'enfance et de l'adolescence, 64:31-5.

[40] Saurel-Cubizolles MJ, Saucedo M, Drewniak N, Blondel B, Bouvier-Colle MH (2012). Santé périnatale des femmes étrangères en France. Bull Epidemiol Hebd, 2:30-4.

[41] Maggioni C, Margola D, Filippi F (2006). PTSD, risk factors, and expectations among women having a baby: a two-wave longitudinal study. J Psychosom Obstet Gynaecol, 27(2):81-90.

[42] Soderquist J, Wijma B, Wijma K (2009). Risk factors in pregnancy for post-traumatic stress and depression after childbirth. BJOG, 116:672-80.

[43] Adewuya AO, Ologun YA, Ibigbami OS (2006).
Post-traumatic stress disorder after childbirth in Nigerian women: prevalence and risk factors. BJOG, 113:284-8.

[44] Soderquist J, Wijma K, Wijma B (2002). Traumatic stress after childbirth: the role of obstetric variables. J Psychosom Obstet Gynaecol, 23:31-9.

[45] Zaers S, Waschke M, Ehlert U (2008). Depressive symptoms and symptoms of post-traumatic stress disorder in women after childbirth. J Psychosom Obstet Gynecol, 29:61-71.

[46] Goutaudier N, Lopez A, Séjourné N, Denis A, Chabrol H (2011). Premature birth: subjective and psychological experiences in the first weeks following childbirth, a mixedmethods study. J Reprod Inf Psychol, 29(4):364-73.

[47] Arockiasamy V, Holsti L, Albersheim S (2008). Fathers' experiences in the neonatal intensive care unit: a search for control. Pediatrics, 121(2):215-22.

[48] Manning AN (2012). The NICU experience: how does it affect the parents' relationship? J Perinat Neonat Nurs, 26:353-7.

[49] Hays MA, Millet C (2009). Soutien des parents et des nouveaux nés hospitalisés en néonatalogie. Intérêt d'un dispositif de groupe. Arch Pediatr, 16(7):1090-6.

[50] Fones C (1996). Posttraumatic stress disorder occurring after painful childbirth. J Nerv Ment Dis, 184:195-6.

[51] American Psychiatric Association (2013). Diagnostic and statistical manual of mental disorders DSM-5. 5e ed: American Psychiatric Publishing. Arlington VA. 